\title{
Framing of sustainable agricultural practices by the farming press and its effect on adoption
}

\author{
Niki A. Rust ${ }^{1}$ (D) Rebecca M. Jarvis ${ }^{2} \cdot$ Mark S. Reed $^{3} \cdot$ Julia Cooper $^{1}$
}

Accepted: 2 December 2020 / Published online: 21 February 2021

(c) The Author(s) 2021

\begin{abstract}
There is growing political pressure for farmers to use more sustainable agricultural practices to protect people and the planet. The farming press could encourage farmers to adopt sustainable practices through its ability to manipulate discourse and spread awareness by changing the salience of issues or framing topics in specific ways. We sought to understand how the UK farming press framed sustainable agricultural practices and how the salience of these practices changed over time. We combined a media content analysis of the farming press alongside 60 qualitative interviews with farmers and agricultural advisors to understand whether the farming press influenced farmers to try more sustainable practices. Salience of sustainable agricultural practices grew between 2009 and 2020. Many of the practices studied were framed by the press around economic and agronomic aspects, and farmer respondents said the most common reasons for trying sustainable agricultural practices were for economic and agronomic reasons. The farming press tended to use more positive rather than negative tones when covering sustainable agricultural practices. Respondents used the farming press as a source of information, though many did not fully trust these outlets as they believed the farming press were mouthpieces for agribusinesses. Whilst a minority of farmers stated they were motivated to try a new sustainable agricultural practice after learning about it in the farming press, this was rare. Instead, the farming press was used by respondents to raise their awareness about wider agricultural topics. We reflect on the role and power given to agribusinesses by the farming press and what this means for agricultural sustainability.
\end{abstract}

Keywords Agribusinesses · Content analysis · Farming press · Framing $\cdot$ Salience $\cdot$ Sustainable agriculture

\section{Introduction}

Politicians, communication scholars and lobbyists are often acutely aware of the power the media hold in shaping public opinion. By curating and sharing specific information widely across society, the media can decide what content their audiences should read (Entman 2007; Scheufele and Tewksbury 2007), indicate what societal values should

Niki A. Rust

niki_rust@hotmail.co.uk

1 Centre for Rural Economy, School of Natural and Environmental Sciences, Newcastle University, Agriculture Building, Kings Road, Newcastle NE1 7RU, UK

2 School of Science, Auckland University of Technology, Auckland 1010, New Zealand

3 Thriving Natural Capital Challenge Centre, Department of Rural Economies, Environment \& Society, Scotland's Rural College (SRUC), Peter Wilson Building, Kings Buildings, West Mains Road, Edinburgh EH9 3JG, UK be highlighted (Kellstedt 2000), determine how issues are framed (Greenberg and Hier 2009), shape political agendas (Soroka 2002), influence attitudes of the general public (Ahchong and Dodds 2012), and promote certain ideologies over others (Lowe and Morrison 1984). Understanding how media outlets cover topical issues can therefore be useful in studying social phenomena (Farr 1993) to help us understand how media institutions reflect, debate and define social reality (Gurevitch and Levy 1985).

Press coverage of agricultural topics can affect policy decisions and public attitudes towards subjects, such as genetically modified foods (Shaw 2002), antibiotic use in livestock (Steede et al. 2019) and biofuels (Delshad and Raymond 2013). Farmers regularly use the farming press to collect new information on relevant agricultural topics (Shimoda et al. 1992; Defra 2019). The way in which the media cover farming issues can affect agricultural policy support and farmer decision making (Ehlers and Sutherland 2016). For instance, news articles on precision farming can influence farmers' decisions to adopt this technology (Kutter 
et al. 2011). Whilst often not the main motivator, the media can help shape farmer behaviour through framing of risks or costs and benefits or opportunities (Pezzullo and Cox 2017) or by favouring specific sources that promote or oppose certain technologies and ideologies (Lyytimäki 2018). It is therefore clear that the farming press has the potential to change how farmers perceive and use more sustainable agricultural practices though, to date, no study has combined interviews with farmers with a media content analysis of the agricultural press to determine why farmers decide to change their practices and if the farming press influenced this decision.

The intensification of agricultural methods over the last half of the twentieth century led to a dramatic increase in yields, lower food prices, increased caloric intake and gains in health and life expectancy (Evenson and Gollin 2003). However, this intensification has also destabilised the Earth's system and contributed to transgression of planetary boundaries for biosphere integrity and biogeochemical flows (Campbell et al. 2017). There is now a drive to meet projected increases in global food demands by increasing yields per hectare, while at the same time minimising environmental damage: this is the new agricultural paradigm of 'sustainable intensification' (Tilman et al. 2011). Dicks et al. (2019) conducted a survey of UK farmers and identified a range of agricultural practices that could deliver sustainable intensification including the use of stress-tolerant or improved crop varieties, precision agriculture technologies, reduced tillage or no-till methods, and rotations with legumes. Microbial inoculants for plant growth promotion (Berg 2009) and new fertiliser technologies that reduce losses to the environment (e.g. polymer-coated urea (Soon et al. 2011)) also show promise as sustainable agricultural products.

Uptake of more sustainable agricultural practices has, however, often been limited (Lahmar 2010; Merante et al. 2017; Alskaf et al. 2020). For instance, one study found only a third of English arable farmers used reduced tillage (Townsend et al. 2016). This lack of uptake is due to a range of reasons, such as agronomic, economic, biophysical, informational, technical, policy and socio-psychological factors influencing behaviour (Prager and Posthumus 2010; Baumgart-Getz et al. 2012; Ulrich-Schad et al. 2017). Each factor can enable or constrain adoption, but a key overarching aspect is knowing about the product or practice, including the benefits and risks (Rogers 2003; Feliciano et al. 2014; Carlisle 2016).

One way to raise awareness of sustainable agricultural practices is via the media. The farming press is an important source of information for farmers to learn about agricultural news (Defra 2019). Despite the abovementioned manifold ways in which the media can change our values, attitudes, behaviour, and ultimately our society, there has been no known study to date that combines a media content analysis with farmer interview respondents to determine whether farming press does encourage adoption of new agricultural practices. This is critical because if the media can influence farmers to try new practices, the media could assist the transition to more sustainable forms of farming. We therefore sought to address this knowledge gap using a case-study approach focusing on UK farming.

We draw upon two theories to situate our study. Rogers' (2003) diffusion of innovation theory suggests that information shared in a network can lead to innovation uptake; this happens once the information received is converted into knowledge and action through the process of interest, evaluation, trial and ultimately uptake (Beal et al. 1956). As the agricultural press are a common source of information for farmers (Defra 2019) it is possible that, by spreading awareness about sustainable agricultural technologies and practices widely within the farming community, the farming press could influence uptake of these measures.

We also consider framing theory (Shaw 1979). The media can manipulate discourse to set agendas (Adams et al. 2014) by changing how an issue is framed. Frames are "persistent patterns of cognition, interpretation, and presentation, of selection, emphasis and exclusion by which symbol-handlers routinely organize discourse" (Gitlin 1980, p. 7). Framesetting is the interaction between how the media frames an issue and the audience's knowledge and predispositions towards that issue (de Vreese 2005). Frames can alter how someone learns about, understands and evaluates a phenomenon, which can alter their attitudes and behaviours, as well as societal and political decisions (Entman 2007). Frames manipulate people by emphasising some aspects of a topic whilst ignoring others. This can be done via repeating specific words, phrases or images, which can increase the memorability and salience of particular views and ultimately can change the acceptance of specific knowledge claims (Marks et al. 2007; Naylor et al. 2017). For instance, merely altering synonyms for "genetic modification" into "genetic engineering" or "agbiotech" can result in higher perceived benefits and support by readers (Zahry and Besley 2019). The presence or absence of certain frames in news articles has the power to shape rural perceptions of agricultural topics (Selfa et al. 2015). Frames can also alter perceptions of topics by manipulating tones, which can alter public support of policies (Thomson and Dininni 2005; Rust 2015). Understanding the tones of how sustainable agricultural products and practices are framed in the farming press would therefore provide insight into how these tones could affect readership perceptions of these methods.

The ability of the media to alter audience's perceptions and behaviour can also be influenced by how it changes the salience of topics. Salience is the prominence of certain aspects of topics (Roberts et al. 2002), which can affect the public's perceived priority over and opinion on the issue 
(McCombs and Ghanem 2001; Marks et al. 2007). Salience is related to issue attention, whereby the public's attention on particular issues gains and loses prominence over time, often in predictable ways (Downs 1972). The key themes that are focused on and repeated by the media over time are more likely to be the most salient in the audience's minds (Scheufele and Tewksbury 2007). It is therefore possible that by making specific agricultural practices more (or less) salient to the reader, the farming press could influence farmers' awareness and use of these practices. Using a case study set in the UK, we sought to understand how the farming press framed sustainable agricultural practices and to what extent the farming press influenced farmers to use these practices.

\section{Method}

\section{Content analysis}

TheNexis News ${ }^{\mathrm{TM}}$ online database was used to search for articles published in Farmers Weekly and Farmers Guardian, which are the two most frequently read farming magazines in the UK. As of 2019, Farmers Weekly had a weekly circulation of 41,000 (ABC 2020a) and Farmers Guardian had a weekly circulation of 28,000 (ABC 2020b). For the content analysis, we focused on six sustainable arable practices and products, selected as showing the most potential to improve nutrient and water use efficiency by scientists and partners from the agricultural sector in the EU Horizon 2020 project SolACE (upon which this research is partly based): precision agriculture, reduced/no tillage, improved crop breeding, fertiliser technologies, grain legumes in rotation and microbial inoculants/biostimulants. ${ }^{1}$ The Boolean queries that were used in the Nexis News search are shown in Table 1; this search sourced all indexed articles available online in the two outlets from 1 January 1998 (when articles were first archived online) until the date of the search on 14 February 2020.

In line with a similar study (Batel 2020), duplicate and irrelevant articles were excluded from the analysis, which resulted in 12,883 articles, the corpus to be analysed (i.e. the structured set of texts), and included news reports, letters to the editor and op-eds. Similar to Liu et al. (2008), this corpus was used to track issue salience (i.e. volume of articles) over time of the six sustainable agricultural practices. For the frame analysis, we selected a sample from the corpus to allow for more manageable qualitative analysis by choosing a random sample of 50 articles from each of the six searches,

\footnotetext{
${ }_{1}^{1}$ Details of how these practices were chosen are on the project website https://www.solace-eu.net/
}

which resulted in the final dataset for the frame analysis (amounting to a total of 300 articles).

The frame analysis followed a similar qualitative process set out in Delshad and Raymond (2013) with themes and sub-themes of each frame devised inductively as articles were read and analysed. The unit of analysis was the sentence rather than the article, as numerous frames and tones could be found within a single article. Sentences within the articles were then coded for the frames and (where present) the tones, which could be positive (related to benefits) or negative (related to risks). Salience of the frames was indicated by the frequency each frame was used in the 300 sampled articles. To check intercoder reliability, a random selection of 50 articles were recoded by a second coder who had been trained in the coding protocols (Supplementary materials), which resulted in an overall average of $83 \%$ reliability for all codes; an intercoder reliability percentage of $80 \%$ or more is considered reliable (Poindexter and McCombs 2000).

\section{Interviews}

We undertook semi-structured interviews, conducted throughout 2019, with UK farmers and those who advised farmers on agricultural matters. An interview guide (Supplementary Materials) was trialled on a subset of the target population to check for wording clarity. Questions posed related to what prompted farmers to try a more sustainable agricultural practice, which sources respondents used to find information on sustainable agriculture, which of these they trusted and why, and their perceptions of the farming press as a source of information. A purposeful sampling strategy (Emmel 2013) was used to source respondents in the following ways:

1. Targeting UK agricultural advisers through online agricultural databases,

2. Contacting UK regional farming groups nationwide,

3. Snowball sampling where respondents recommended further individuals to interview.

We chose a purposeful sampling strategy to obtain a range of farmers from across the UK representing different geographic regions (England: 17, Scotland: 12, Wales: 3), farming types (arable: 18, mixed: 12, horticulture: 2 ) and farming systems (conventional: 20, organic: 12). Because of the diverse and fragmented farm advisory landscape (Klerkx and Proctor 2013) we also targeted a range of different types of advisers (Table 2). All respondents were offered prior informed consent to take part in the research and accepted verbally. New respondents were sourced until no new themes emerged from the data, which suggested that theoretical saturation had been reached. A total of 
Table 1 Search terms used in Nexis News TM to source articles on sustainable agricultural practices published online in Farmers Weekly or Farmers Guardian 1998-2020, plus the number of articles retrieved from these searches and sampled for analysis

Sustainable agricultural practice Search term used

\begin{tabular}{ll}
$\begin{array}{l}\text { Number } \\
\text { of articles } \\
\text { retrieved }\end{array}$ & $\begin{array}{l}\text { Number of articles } \\
\text { randomly sampled }\end{array}$ \\
\hline
\end{tabular}

Percentage of articles

retrieved $(\%)$

Fertiliser technologies

Improved crop varieties

Microbial inoculants

Precision agriculture

Reduced/no tillage

Rotations with grain legumes

Total

\begin{abstract}
"Organic fertiliser" OR "organic fertilizer" OR "compost fertiliser" OR "manure fertiliser" OR (fertiliser AND (manure OR slurry OR compost OR digestate OR biosolids OR "poultry litter" OR "green waste" OR "fertiliser additive" OR "slow release" OR sludge)

Crop AND (variety OR varieties OR cultivar
\end{abstract} OR cultivars OR breeding OR hybrid OR hybrids OR genotype OR genotypes OR breeding OR populations)

((Inoculant OR inoculants OR inoculum OR soil) AND (Pseudomonas OR Bacillus OR Arbuscular OR Mycorrhizal OR Fungi OR AMF OR Trichoderma OR microbial OR microbe OR microbes OR rhizobia)) OR (rhizobacteria OR PGPR OR biofertiliser OR biostimulant)

((Nitrogen OR phosphorus OR "nutrient management" OR "nutrient efficiency" OR "water efficiency" OR "water use efficiency" OR irrigation OR irrigate) AND (tool OR software OR "decision support" OR app OR drone OR gps OR technology OR UAV OR optimisation OR precision OR satellite OR "digital agriculture")) OR ((variable-rate OR (irrigation AND efficient) or (irrigate AND efficient) OR (irrigation AND app) OR (irrigate AND app))

No-till OR notill OR "no tillage" OR "zero tillage" OR "conservation tillage" OR "reduced tillage" OR "minimum tillage" OR mintill OR "direct drill" OR "direct drilling"

((Rotation OR rotational OR rotations) AND (alfalfa OR clover OR beans OR peas OR chickpeas OR lentils OR lupins OR mesquite OR carob OR soybeans OR peanuts OR tamarind OR precrop)) OR ((rotation OR rotations OR rotational OR precrop) AND (lucerne OR pulses OR legumes))

\begin{tabular}{|c|c|c|}
\hline 1499 & 50 & 3.33 \\
\hline 9231 & 50 & 0.5 \\
\hline 380 & 50 & 13.16 \\
\hline 1692 & 50 & 2.96 \\
\hline 1247 & 50 & 4.01 \\
\hline 1552 & 50 & 3.22 \\
\hline 5,601 & 300 & Mean 4.53 \\
\hline
\end{tabular}

first author retrospectively using thematic analysis by first reading the transcripts to get an overview of the interviews and then coding each one based on common themes emerging from the data. Themes were developed a posteriori during the course of the coding as described in Braun et al. (2015). Anonymised quotes are used in the Results where this provides an example of the themes. The study obtained ethical approval from the Newcastle University Ethics Committee. 
Table 2 Characteristics of semi-structured interview respondents

\begin{tabular}{ll}
\hline Profession & Gender \\
\hline Adviser: (28) & $\mathrm{F}(13)$ \\
Farming association & $\mathrm{M}(15)$ \\
$\quad$ (2) & \\
University/college (5) & \\
Environmental NGO & \\
$\quad$ (3) & \\
Government (2) & \\
Independent (7) & \\
Agribusiness (6) & \\
Agricultural levy & \\
$\quad$ board (5) & \\
Farmer: (32) & $\mathrm{F} \mathrm{(5)}$ \\
Arable (13) & $\mathrm{M}(27)$ \\
Mixed (19) & \\
\hline
\end{tabular}

\section{Results}

\section{How has the volume of reporting on sustainable agricultural practices changed over time?}

There were no notable differences in how the two outlets covered the topics, hence these are discussed collectively (Supplementary materials). To indicate issue salience, the number of articles published in the two farming press outlets between 1998 and 2020 for each of the six sustainable agricultural practices was plotted against time and compared with the total number of articles published for each outlet (Fig. 1). Substantially more articles were published on crop breeding than the other practices analysed, with the lowest number of articles published on microbial inoculants (though noting this topic saw a more rapid increase in volume of articles published since 2010). Most of the six practices had an increasing salience since 2009, despite a decline in the total number of articles published in the two outlets since 2014. This suggests an increase in salience of these sustainable agricultural practices compared with other topics published in these outlets. In 2001 and 2009, there were two instances where coverage of all articles on the six practices (as well as total number of articles published) were low, which coincided with two economic downturns in the country.

\section{How are sustainable agricultural practices framed by the farming press and what are their tones?}

Coding of the 300 randomly sampled articles resulted in seven broad frames of sustainable agricultural practices (Table 3). Overwhelmingly, the two most common frames used by the two farming press outlets related to economic and agronomic aspects of the sustainable agricultural practices. There was, conversely, limited discussion of the environmental benefits of using these practices, suggesting economic sustainability was deemed more important to cover than environmental sustainability.

Within the economics frame, the main sub-theme used by the press related to profits and expenditures, including discussions around yields, agricultural markets and policies to increase farm profits. There was frequently an implied association between increased yields and increased profits. As an example, an article focusing on a precision agricultural tool stated "most of the financial gain comes from additional yield. By reducing canopy over-development, yields have increased". This article's
Fig. 1 Number of articles published on each of the six sustainable agricultural practices analysed (log. $10 \mathrm{y}$-axis) plotted alongside the total number of articles published in Farmers Weekly and Farmers Guardian 1998-2020

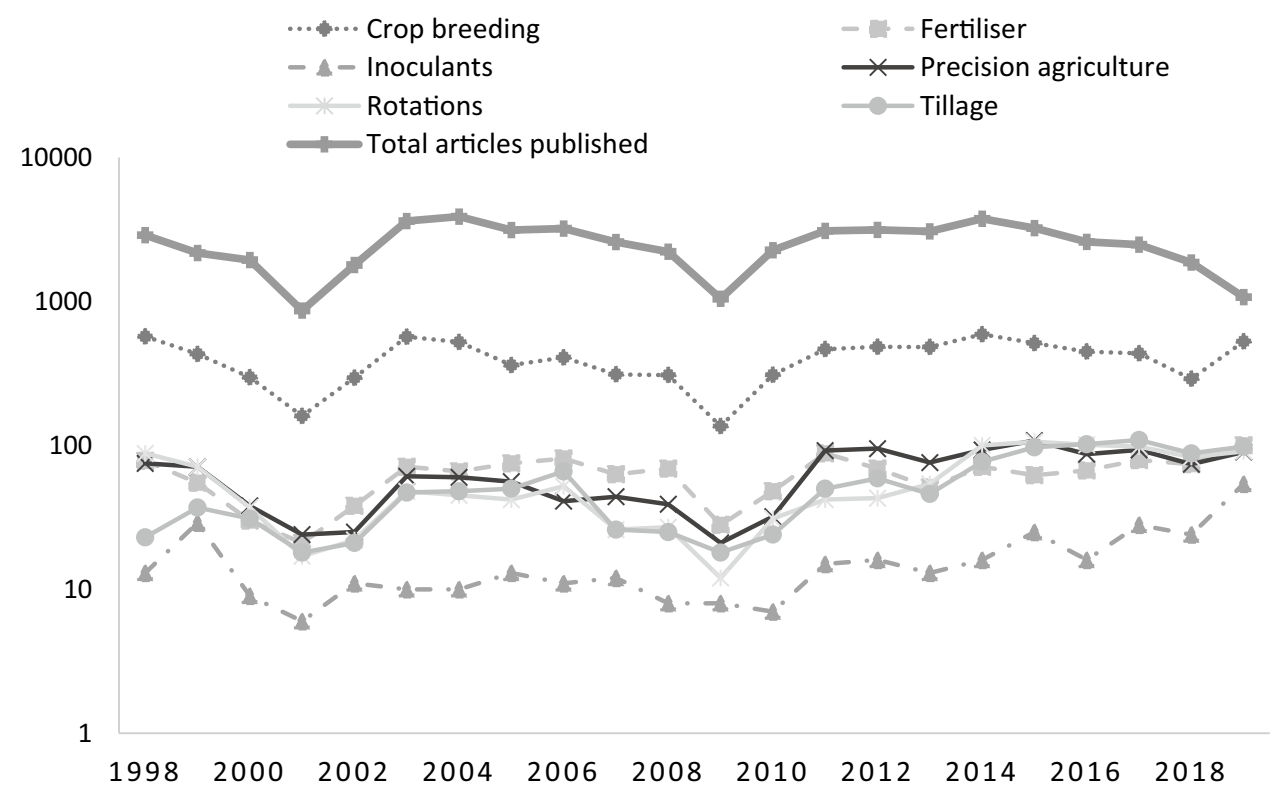




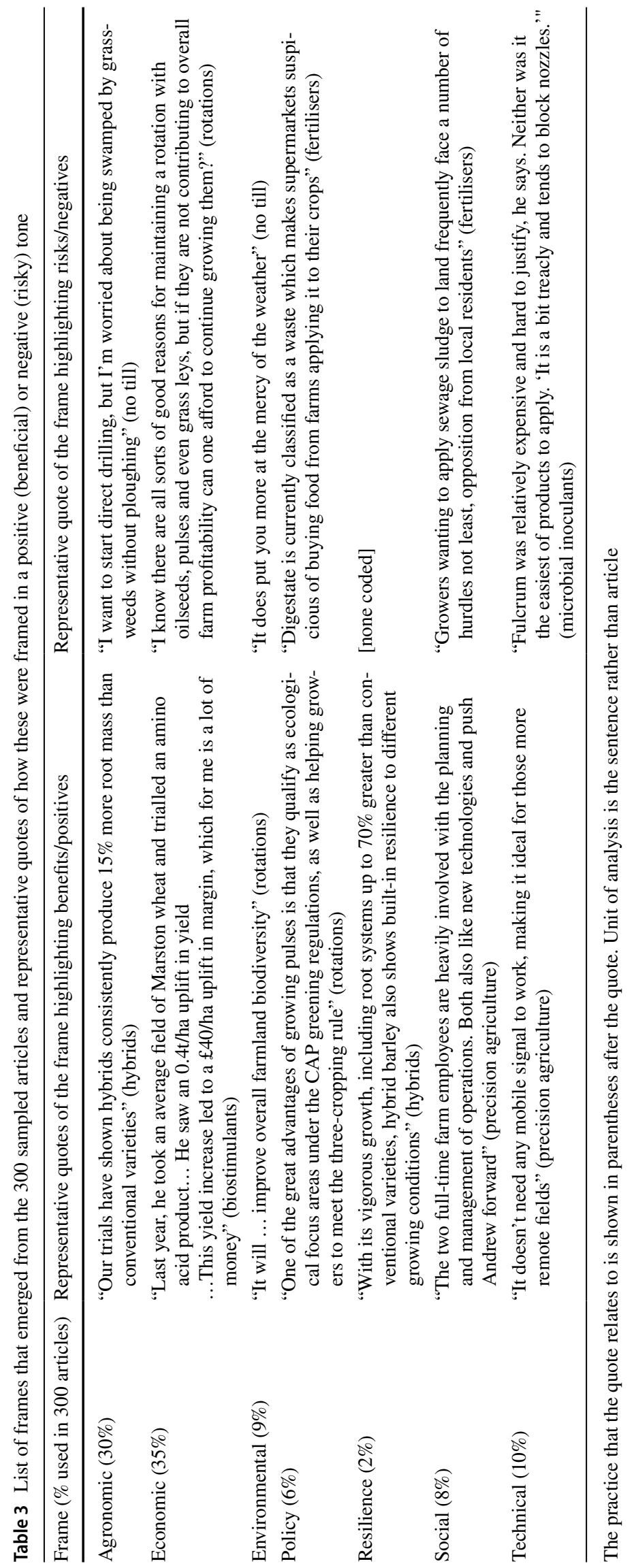




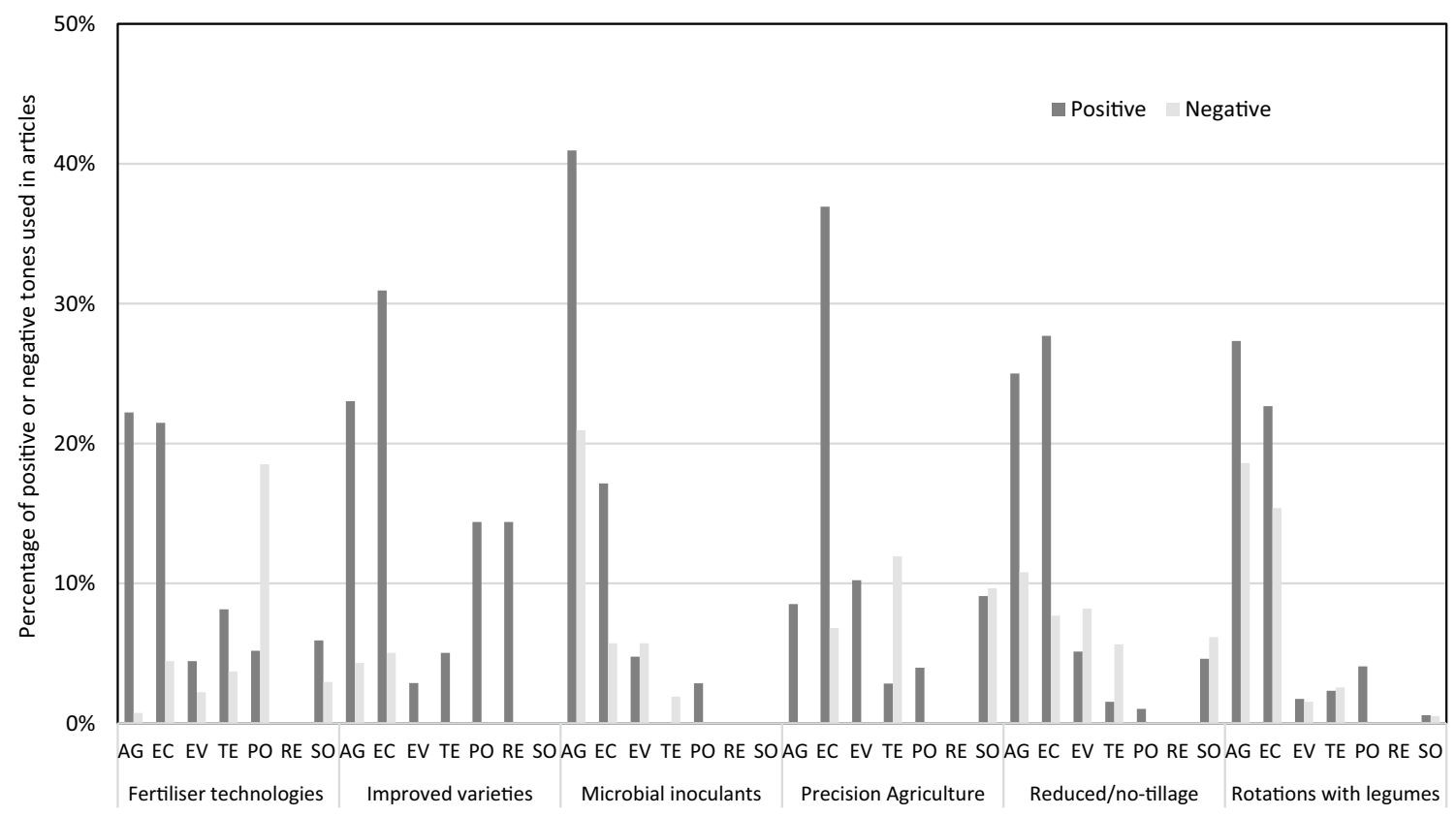

Fig. 2 Percentage of times positive and negative tones were used to frame the six sustainable intensification technologies $(A G=a g r o n o m i c$, $\mathrm{EC}=$ economic, $\mathrm{EV}=$ environmental, $\mathrm{TE}=$ technological, $\mathrm{PO}=$ political, $\mathrm{RE}=$ resilience, $\mathrm{SO}=$ social; $\mathrm{n}=300$ ). Unit of analysis was the sentence

title ("Being precise helps raise profit; Want to add money to the bottom line?") implied that the use of precision agriculture technologies would increase yields and profits, yet did not disclose the actual profits, making it hard for farmers to understand the net benefits of these technologies. Whilst increased yields can increase profits, the cost of some of the expensive precision agricultural technologies was often not discussed but can be prohibitively expensive, particularly for small-scale farmers, meaning profits may remain the same or indeed may decrease. This suggest that the outlets were often focusing on the productionist narrative that "yield is king".

For the agronomic aspects, articles often focused on how the sustainable practice affected crop growth. These articles highlighted both the risks and benefits of the technology, with benefits focused on how yields would increase, whilst risks were primarily linked to increased challenges with pests and diseases. For the sustainable agricultural practices studied that related to a commercial product (e.g. microbial inoculants, improved varieties, fertiliser additives and precision agriculture), interviews by the press were often conducted with the company selling the product, who professed the benefits of the technology. There was, however, limited attention paid to independent sources to verify these claims.

We next analysed how the farming press covered each of the six sustainable agricultural practices that we focused on in our study, including how these practices were framed and the tone of these frames (Fig. 2).
Fertiliser technologies whilst this technology was covered primarily in a more positive tone (67\%), especially related to agronomic (22\%) and economic benefits (21\%), it was also covered negatively (33\%). This technology had the highest proportion of negative policy tones (19\%) of all the six sustainable agricultural practice analysed, particularly related to concerns around current and potential policy changes that could limit organic and inorganic fertiliser use.

Improved varieties this sustainable agricultural practice was frequently discussed positively, having the highest proportion of positive tones $(91 \%)$ versus negative tones (9\%) of the six practices analysed. The small instances that negative tones were used related to agronomic aspects of increased disease risk (4\%) and economic aspects related to costs of the hybrids and varieties versus conventional options (5\%).

Microbial inoculants this technology had a high proportion of positive tones (66\%) related to agronomic aspects (41\%), such as plant growth, health and disease resistance. However, inoculants also had a higher proportion of agronomic negative tones (21\%) than other sustainable agricultural practices, often related to insufficient evidence showing beneficial crop effects. Whilst there were bold claims from product suppliers that had been interviewed by the press on the apparent effectiveness of the technologies, these efficacies were disputed by other people interviewed by journalists (notably farmers and independent scientists) due to insufficient on-farm trials.

Precision agriculture often, the benefits of these technologies were conveyed primarily around improved efficiency 
(and therefore economic benefits; 37\%) rather than for environmental benefits (10\%) of lower inputs. When environmental aspects were discussed, this was usually in relation to the technology allowing the farmer to comply with environmental regulations. The most common negatively framed tone related to technical issues (12\%), particularly around learning how to use the new technology, as well as whether it would be compatible with existing technology, concerns over unreliability and lack of widespread testing.

Reduced/no-till the tones here were primarily framed around agronomic and economic positives and negatives. Whilst reduced tillage has previously been purported in the academic literature to be beneficial for the environment (Krauss et al. 2017), this practice was rarely framed as such in the farming press $(10 \%)$. As one farmer said in a press article interview: "I'm not here to keep bugs and worms in the soil for the sake of it, I want something back for it". Reduced tillage also exhibited negative tones related to agronomic aspects (11\%), particularly around the increased challenges with dealing with crop pests and being able to direct drill in wet weather, and economic risks (8\%) such as the cost of the machinery needed for direct drilling.

Rotations with grain legumes this practice was frequently discussed in an agronomic frame, especially with negative tones (19\%) related to pests and diseases arising from this practice, and agronomic positive tones (27\%) related to nitrogen fixation properties of the legumes to reduce fertiliser inputs. Rotations with grain legumes had the highest proportion of negative tones overall (41\%), again related to agronomic and economic aspects. Peas, for instance, were regularly cited as having agronomic challenges due to disease and difficulties with growing in unfavourable weather. Economic concerns focused on the markets for grain legumes being volatile and the premium market for human consumption being difficult to access due to the high-quality requirements that can be hard to obtain in British weather conditions.

\section{Do farmers and advisers use the farming press to gain information about sustainable agricultural practices and does this lead to uptake?}

Of the 32 farmers interviewed for this study, the majority $(n=22)$ said that they tried a new sustainable farming practice due to economic reasons, followed by agronomic $(n=10)$, technical $(n=9)$ and environmental $(n=8)$ reasons. $^{2}$ Social, political, and resilience reasons were not mentioned. Respondents used a range of sources to gather information about sustainable agriculture. It was rare for respondents

\footnotetext{
$\overline{2}$ Respondents could mention more than one reason why they tried a more sustainable approach.
}

to use a single source of information. Instead, they tended to go on a journey of information gathering after they first learnt something: if they were interested in converting this information to knowledge and practice, they would then look for additional sources to determine whether this information was supported elsewhere. Many farmers interviewed used the farming press as a source of information about sustainable agriculture and was frequently named the first place they learnt about a new agricultural technology. There was concern, however, that outlets and articles were part-funded by agribusiness via adverts and advertorials, so the farming press was deemed to be biased and untrustworthy, as exemplified by an arable farmer respondent interviewed: "some of the articles you can kind of see influenced by advertisers and machinery suppliers". Farmers interviewed were also aware that the farming press often painted a more positive story about agricultural technologies than in reality, as a mixed farmer explained:

I think when you open up the Farmers Weekly or any other farming magazine it is always full of wonderful success stories where people have said how wonderful something is and I am always a little bit suspicious of such fantastic success stories.

Advisers interviewed were more critical than farmer respondents of using the farming press as a main source of sustainable agricultural information, primarily due to the perception of biased reporting in favour of agribusiness and wanting to maintain the status quo, as summarised in this quote from an agronomist:

One example would be in the farming press and sometimes they have pieces on a particular way of doing things, but it is actually just a press release that has been turned into an article. The press release may have come from a company that is trying to sell something.

Whilst respondents were aware of the lack of credibility that the farming press suffered from, some advisors said they still read the farming press to keep up-to-date with the information that farmers had been exposed to, so they could better understand their clients. However, they were clear that they did not use the farming press to provide advice to clients on sustainable agriculture but rather turned to what they deemed more credible sources, such as peer-reviewed scientific journal articles and in-house research produced from their own advisory companies.

When it came to understanding what prompted farmers to try a new sustainable agricultural practice, many said they were primarily influenced by another farmer or an advisor that they knew, trusted and had a long-term relationship with. Often, the decision to try a new practice was due to numerous factors related to economics, a willingness to try something new, coupled with knowing someone who 
had already tried it and seen financial success with using it. However, rarely it was indeed sufficient for a farmer to read about a new sustainable agricultural innovation in the farming press to convince them to change, as one arable farmer explained when talking about trying a new type of fertiliser:

I think I read about it from a farming magazine. I have checked other farming publications also... I thought why not. I was trying it to see if the crop would improve.

Often, though, the farming press was primarily used as an awareness raising tool, as summarised by a mixed farmer:

You would read it and think it is interesting and it would maybe give you another layer of knowledge but you wouldn't necessarily rush out and do it.

The farming press was therefore reported to be used as only one layer of information gathering but was not usually reported to be the main factor in motivating farmers to adopt sustainable agricultural practices.

\section{Discussion}

This research sought to understand how the UK farming press framed sustainable agricultural practices and if the farming press influenced farmers to try these practices. We found that, since 2009 , the UK farming press has increased reporting of the six sustainable agricultural practices analysed in this study, despite a decline in the total number of articles published in the two outlets studied. This finding contrasts with earlier research that noted the farming press exhibited limited attention towards more sustainable farming (Walter 1995), suggesting increased salience of these six sustainable agricultural practices in the UK farming press since 2009. One of the reasons for this could be due to more awareness on the environmental impacts of farming alongside the need to improve the sustainability and resilience of agriculture (Poore and Nemecek 2018; Nyström et al. 2019; Rust et al. 2020a). Given the rise in regulatory mechanisms to reduce agricultural impacts on the environment, associated with national pressure to meet the United Nations Sustainable Development Goals, the farming press may also be increasingly focusing on sustainable agricultural topics to help prepare readers for future regulatory changes. Equally, farmers themselves may be using more sustainable agricultural practices now more than in the past, therefore the farming press could be reflecting this change in farmer behaviour.

The farming press most frequently framed sustainable agricultural practices around agronomic and economic aspects, such as increased yields and productivity, with little focus on environmental benefits. The farmers that we interviewed mentioned their main reasons for trying sustainable agricultural practices were due to economic reasons followed by agronomic reasons. Conversely, environmental motivations to become more sustainable were rarely mentioned in our interviews, and when they were, the reasons tended to be associated with agronomic or economic benefits, such as improved crop growth or reduced fertiliser bills. This suggests that sustainable agricultural practices being framed primarily in economic and agronomic ways by the farming press aligns with farmer respondents' reasons for changing their practices and thus suggests these frames are salient. A recent nationwide UK study found the main reasons why farmers decided to innovate was for economic reasons (Defra 2019); when combined with our study's findings, this suggests that British farmers in general were not as interested in reducing their farm's environmental impact as they were about supporting their bottom line. It is not clear whether the farming press is influencing farmers' focus on economic and agronomic aspects above environmental benefits or whether the farming press is reflecting its readers' sentiments and behaviours (Walter 1995) thus the farming press's role in setting agendas on this topic is unclear. Similar to a review on how the Canadian press covered the topic of GM alfalfa (Tourangeau 2018), our findings also suggest the neoliberal discourse of the farming press could overpower other narratives such as social, environmental or political aspects.

The British farming press tended to frame sustainable agricultural practices in more positive tones than negative in the articles analysed. The reasons for this are unclear but could be linked with the income received from agribusinesses who advertise in their magazines (Thomas 2011) where editors may be swayed by advertising income to ensure advertised products are shown in a favourable light. Previous studies have noted the power that agricultural advertisers have in influencing farming press content (Hays and Reisner 1990, 1991). Coupled with declining sales of farming magazines (ABC 2020a, b), this could result in outlets being more tempted to align their content with the values of their main advertisers (Walter 1996). The distrust many respondents in our study exhibited towards the credibility of information shared in the farming press was reported to be associated with this close relationship between the farming press and the advertisers, as respondents thought the content of the outlets was swayed by advertisers. Agritech companies interviewed by the farming press professed the benefits of their products, though reporters rarely included independent sources to verify claims, such as from farmers who had tried the products in the field. Conversely, for the sustainable agricultural practices such as reduced tillage and using legumes in rotation, reporters were more likely to interview farmers, who reported both positive and negative aspects of the practice. This could indicate that, where money is to be made by agribusiness for promoting specific products, like 
precision agricultural technology, the farming press covers these products in a more favourable light than with practices that are more focused on changes in management. In 1989, Reisner and Hays undertook a survey of agricultural journalists to determine how advertising pressure affected reporting. They found that reporters were concerned with the pressures that the advertising industry had on agricultural journalism and concluded that "advertising abuses are a clear and present danger" to farming press objectivity (Reisner and Hays 1989). Lodgson (1992, p. 54) noted "collusion between advertisers and editors is a clear and present danger, particularly in times when publications are struggling economically", suggesting it is not the media per se who decide how to frame sustainable agriculture but rather the advertisers who coerce the farming press into altering coverage of these topics. Future studies could repeat a similar methodology to Reisner and Hays (1989) to interview farming journalists and editors to understand how they choose topics to cover and the extent to which advertisers influence this choice and the framing they use.

When it came to understanding what prompted farmers to try sustainable agricultural practices, a few farmers that we interviewed reported they innovated based on reading about the new practice or technology in the farming press, though this was rare. Most farmers interviewed required additional verification from trusted sources such as farmers they knew and respected to triangulate the information, as shown elsewhere with how the general public corroborates news articles (Zaryan 2017). To many of the farmers we interviewed, the farming press was an important source of information to learn about new agricultural topics, suggesting the farming press does play a role in awareness raising, but most respondents treated the articles with suspicion, especially if they felt articles were written primarily to promote companies or products. Trust in the generalised media by the public is at a low (Newman et al. 2020), which could mean that the ability for the media to set agendas could also have diminished. However, given that individuals are indirectly influenced by their environment in ways they may perhaps not directly be cognisant of, it is possible that the farming press could subtly change attitudes and behaviour of farmers in ways that farmers may not be immediately aware of. More research is needed on this to determine the extent to which the farming press indirectly influences farmer behaviour and future studies would benefit from larger, random sample sizes.

That the farming press has been shown in this study to be a common source of information for farmers indicatesits potential for setting agendas on sustainable agricultural topics and, as salience of articles on sustainable agriculture have risen, it is possible that this has had a knock-on effect to raise awareness of sustainable agricultural practices amongst its readers. ${ }^{3}$ The Diffusion of Innovations theory suggests that, in order for a new behaviour to be adopted, the first steps in the process are to gather knowledge and be persuaded (Rogers 2003). The farming press could therefore act as an enabler of increased knowledge transfer around sustainable agricultural practices, where we propose that interested farmers then seek additional information from the farming press in order to be persuaded whether to try the new practice. Farmers, in general, place most trust in the farming advice from other farmers and are more likely to act on advice from farmers than non-farmers (Rust et al. 2020b). Therefore, it could be useful for journalists and editors to consider sourcing more balanced interviewees, particularly from other farmers, with less reliance on agribusiness sources.

\section{Conclusion}

The media have the power to set public and political agendas (Wanta et al. 2004). The farming press can shape farmer agendas too so they could be an important influencer in farmer decision making and may influence uptake of sustainable agricultural practices. However, in our study, whilst the salience of sustainable agricultural topics has risen since 2009 , and most farmers interviewed in our study used the farming press as a source of agricultural information, many farmers said they were not motivated to try more sustainable practices solely by reading the farming press alone. Instead, the farmers we interviewed relied more heavily on other sources, such as trusted and empathetic farmers, to influence their decision to innovate. It is therefore not clear the extent to which the farming press has influenced farmers in using more sustainable agricultural practices. It could be that farmers, as customers of the farming press, influence the agenda of the agricultural media (Delshad 2012), or that farmers and the media influence each other. Whilst the farming press may not frequently directly change farmer behaviour, we have found its importance in raising awareness of sustainable agricultural issues, which is one step in the process of adopting an innovation. This awareness raising process can direct farmers to further explore new ideas and practices in their journey of knowledge generation on sustainable agriculture.

Supplementary information The online version of this article (https:// doi.org/10.1007/s10460-020-10186-7) contains supplementary material, which is available to authorized users.

\footnotetext{
3 Though, as mentioned above, could also reflect farmer behaviour rather than be influencing it.
} 
Acknowledgements This research was funded by the European Union Horizon 2020 project grants SolACE (727247) and SoilCare (677407).

Open Access This article is licensed under a Creative Commons Attribution 4.0 International License, which permits use, sharing, adaptation, distribution and reproduction in any medium or format, as long as you give appropriate credit to the original author(s) and the source, provide a link to the Creative Commons licence, and indicate if changes were made. The images or other third party material in this article are included in the article's Creative Commons licence, unless indicated otherwise in a credit line to the material. If material is not included in the article's Creative Commons licence and your intended use is not permitted by statutory regulation or exceeds the permitted use, you will need to obtain permission directly from the copyright holder. To view a copy of this licence, visit http://creativecommons.org/licenses/by/4.0/.

\section{References}

ABC. 2020a. Farmers weekly. ABC. https://www.abc.org.uk/produ ct/2513. Accessed 19 Jan 2020.

ABC. 2020b. Farmers guardian. ABC. https://www.abc.org.uk/produ ct/3076. Accessed 19 Jan 2020.

Adams, A., A. Harf, and R. Ford. 2014. Agenda setting theory: a critique of maxwell McCombs \& Donald Shaw's theory in Em Griffin's a first look at communication theory. Meta Communicate 4: $1-15$.

Ahchong, K., and R. Dodds. 2012. Anthropogenic climate change coverage in two Canadian newspapers, the Toronto Star and the Globe and Mail, from 1988 to 2007. Environmental Science and Policy 15: 48-59.

Alskaf, K., D.L. Sparkes, S.J. Mooney, S. Sjögersten, and P. Wilson. 2020. The uptake of different tillage practices in England. Soil Use and Management 36: 27-44.

Batel, S. 2020. Re-presenting the rural in the UK press: an exploration of the construction, contestation and negotiation of media discourses on the rural within post-carbon energy transitions. Energy Policy 138: 111286.

Baumgart-Getz, A., L.S. Prokopy, and K. Floress. 2012. Why farmers adopt best management practice in the United States: a metaanalysis of the adoption literature. Journal of Environmental Management 96: 17-25.

Beal, G.M., J.M. Bohlen, L. Coleman, H.G. Lionberger, E.A. Wilkening, R.M. Dimit, N. Gross, and B. Ryan. 1956. The diffusion process: special report $N^{\circ} 18$, agricultural experiment station 18 , agricultural experiment station. Ames, Iowa: Iowa State College.

Berg, G. 2009. Plant-microbe interactions promoting plant growth and health: perspectives for controlled use of microorganisms in agriculture. Applied Microbiology and Biotechnology 84: 11-18.

Braun, V., V. Clarke, and N. Hayfield. 2015. Thematic analysis. In Qualitative psychology: a practical guide to research methods, ed. Jonathan A. Smith, 222-248. London, UK: Sage Publications.

Campbell, B.M., D.J. Beare, E.M. Bennett, J.M. Hall-Spencer, J.S.I. Ingram, F. Jaramillo, R. Ortiz, N. Ramankutty, J.A. Sayer, and D. Shindell. 2017. Agriculture production as a major driver of the earth system exceeding planetary boundaries. Ecology and Society 22: 4.

Carlisle, L. 2016. Factors influencing farmer adoption of soil health practices in the United States: a narrative review. Agroecology and Sustainable Food Systems 40: 583-613.

de Vreese, C.H. 2005. News framing: theory and typology. Information Design Journal \& Document Design 13 (1): 51.
Defra. 2018. Farm structure survey 2013: focus on agricultural labour in England and the United Kingdom. London, UK: Defra.

Defra. 2019. Farm practices survey 2018-England. London, UK: Defra.

Delshad, A.B. 2012. Revisiting "Who influences whom?" Agenda setting on biofuels. Congress and the Presidency 39: 177-198.

Delshad, A.B., and L. Raymond. 2013. Media framing and public attitudes toward biofuels. Review of Policy Research 30: 190-210.

Dicks, L.V., D.C. Rose, F. Ang, S. Aston, A.N.E. Birch, N. Boatman, E.L. Bowles, et al. 2019. What agricultural practices are most likely to deliver "sustainable intensification" in the UK? Food and Energy Security 8: e00148.

Downs, A. 1972. Up and down with ecology - the "issue-attention cycle." The Public Interest 28: 38-50.

Ehlers, M.H., and L.A. Sutherland. 2016. Patterns of attention to renewable energy in the British farming press from 1980 to 2013. Renewable and Sustainable Energy Reviews 54: 959-973.

Emmel, N. 2013. Purposeful sampling. In Sampling and choosing cases in qualitative research: a realist approach, ed. Nick Emmel, 33-45. London, UK: Sage Publications.

Entman, R.M. 2007. Framing bias: media in the distribution of power. Journal of Communication 57: 163-173.

Evenson, R.E., and D. Gollin. 2003. Assessing the impact of the green revolution, 1960 to 2000'. Science 300: 758.

Farr, R.M. 1993. Theory and method in the study of social representations. In Empirical approaches to social representations, ed. G.M. Breakwell and D.V. Canter, 15-38. Oxford, UK: Clarendon Press.

Feliciano, D., C. Hunter, B. Slee, and P. Smith. 2014. Climate change mitigation options in the rural land use sector: Stakeholders' perspectives on barriers, enablers and the role of policy in North East Scotland. Environmental Science and Policy 44: 26-38.

Gitlin, T. 1980. The whole world is watching. Berkeley, CA: University of California Press.

Greenberg, J., and S. Hier. 2009. CCTV surveillance and the poverty of media discourse: a content analysis of canadian newspaper coverage. Canadian Journal of Communication 34: 461-486.

Gurevitch, M., and M. Levy. 1985. Mass communication review yearbook, vol. 2. Beverley Hills, CA: Sage Publications.

Hays, R.G., and A.E. Reisner. 1990. Feeling the heat from advertisers: farm magazine writers and ethical pressures. Journalism Quarterly 67: 936-942.

Hays, R.G., and A.E. Reisner. 1991. Farm journalists and advertiser influence: pressures on ethical standards. Journalism Quarterly 68: $172-178$.

Kellstedt, P.M. 2000. Media framing and the dynamics of racial policy preferences. American Journal of Political Science 44: 245.

Klerkx, L., and A. Proctor. 2013. Beyond fragmentation and disconnect: networks for knowledge exchange in the english land management advisory system. Land Use Policy 30: 13-24.

Krauss, M., R. Ruser, T. Müller, S. Hansen, P. Mäder, and A. Gattinger. 2017. Impact of reduced tillage on greenhouse gas emissions and soil carbon stocks in an organic grass-clover ley-winter wheat cropping sequence. Agriculture, Ecosystems and Environment 239: 324-333.

Kutter, T., S. Tiemann, R. Siebert, and S. Fountas. 2011. The role of communication and co-operation in the adoption of precision farming. Precision Agriculture 12: 2-17.

Lahmar, R. 2010. Adoption of conservation agriculture in Europe. Lessons of the KASSA project. Land Use Policy 27: 4-10.

Liu, X., A. Vedlitz, and L. Alston. 2008. Regional news portrayals of global warming and climate change. Environmental Science and Policy 11: 379-393.

Logsdon, G. 1992. Filling the white space between the ads. Agriculture and Human Values 9: 54-59. 
Lowe, P., and D. Morrison. 1984. Bad news or good news: environmental politics and the mass media. The Sociological Review 32: $75-90$.

Lyytimäki, J. 2018. Renewable energy in the news: environmental, economic, policy and technology discussion of biogas. Sustainable Production and Consumption 15: 65-73.

Marks, L.A., N. Kalaitzandonakes, L. Wilkins, and L. Zakharova. 2007. Mass media framing of biotechnology news. Public Understanding of Science 16: 183-203.

McCombs, M.E., and S.I. Ghanem. 2001. The convergence of agenda setting and framing. In Framing public life: perspectives on media and our understanding of the social world, ed. S.D. Reese, O.H. Gandy, and A.E. Grant, 67-81. Mahwah, NJ: Lawrence Erlbaum Associates.

Merante, P., C. Dibari, R. Ferrise, B. Sánchez, A. Iglesias, J. Peter Lesschen, P. Kuikman, J. Yeluripati, P. Smith, and M. Bindi. 2017. Adopting soil organic carbon management practices in soils of varying quality: implications and perspectives in Europe. Soil and Tillage Research 165: 95-106.

Naylor, R., W. Manley, D. Maye, G. Enticott, B. Ilbery, and A. Hamilton-Webb. 2017. The framing of public knowledge controversies in the media: a comparative analysis of the portrayal of badger vaccination in the english national, regional and farming press. Sociologia Ruralis 57: 3-22.

Newman, N., R. Fletcher, A. Schulz, S. And1, and R. Kleis Nielsen. 2020. Reuters institute digital news report 2020. Oxford, UK: Reuters Institute and University of Oxford.

Nyström, M., J.B. Jouffray, A.V. Norström, B. Crona, P. Søgaard Jørgensen, S.R. Carpenter, V. Galaz. Bodin, and C. Folke. 2019. Anatomy and resilience of the global production ecosystem. Nature 575 (7781): 98-108.

Pezzullo, P.C., and R. Cox. 2017. Environmental communication and the public sphere, 3rd ed. Thousand Oaks, CA: Sage Publications.

Poindexter, P., and M. McCombs. 2000. Research in mass communication: a practical guide. Boston: St Martins.

Poore, J., and T. Nemecek. 2018. Reducing food's environmental impacts through producers and consumers. Science 360: 987-992.

Prager, K., and H. Posthumus. 2010. Socio-economic factors influencing farmers' adoption of soil conservation practices in Europe. In Human dimensions of soil and water conservation. Napier, TL: Nova Science Publishers.

Reisner, A.E., and R.G. Hays. 1989. Media ethics and agriculture: advertiser demands challenge farm press's ethical practices. Agriculture and Human Values 6: 40-46.

Roberts, M., W. Wanta, and T. Horng Dzwo. 2002. Agenda setting and issue salience online. Communication Research 29 (4): 452-465.

Rogers, E.M. 2003. Diffusion of innovations, 5th ed. New York: Free Press.

Rust, N.A. 2015. Media framing of financial mechanisms for resolving human-predator conflict in Namibia. Human Dimensions of Wildlife 20: 440-453.

Rust, N.A., P. Stankovics, R. Jarvis, J. de Vries, J. Ingram, J. Mills, J. Glikman, J. Parkinson, Z. Toth, and M.S. Reed. 2020. Have farmers had enough of experts? 3005. Newcastle, UK: Newcastle University.

Rust, N.A., L. Ridding, C. Ward, B. Clark, L. Kehoe, M. Dora, M.J. Whittingham, et al. 2020. How to transition to reduced-meat diets that benefit people and the planet. Science of the Total Environment 718: 137208

Scheufele, D.A., and D. Tewksbury. 2007. Framing, agenda setting, and priming: the evolution of three media effects models. Journal of Communication 57: 9-20.
Selfa, T., A. Iaroi, and M. Burnham. 2015. Promoting ethanol in rural Kansas: local framings and cultural politics. Journal of Rural Studies 39: 63-73.

Shaw, E.F. 1979. Agenda-setting and mass communication theory. Gazette 25: 96-105.

Shaw, A. 2002. "It just goes against the grain". Public understandings of genetically modified (GM) food in the UK. Public Understanding of Science 11: 273-291.

Shimoda, T., M.H. Heine, R.C. Woodhouse, and P. Rowlinson. 1992. From where do dairy farmers get their information? Proceedings of the British Society of Animal Production 1972: 124-124.

Soon, Y.K., S.S. Malhi, R.L. Lemke, N.Z. Lupwayi, and C.A. Grant. 2011. Effect of polymer-coated urea and tillage on the dynamics of available $\mathrm{N}$ and nitrous oxide emission from Gray Luvisols'. Nutrient Cycling in Agroecosystems 90: 267-279.

Soroka, S.N. 2002. Issue attributes and agenda-setting by media, the public, and policymakers in Canada. International Journal of Public Opinion Research 14: 264-285.

Steede, G.M., C. Meyers, N. Li, E. Irlbeck, and S. Gearhart. 2019. A content analysis of antibiotic use in livestock in National U.S. newspapers. Journal of Applied Communications 103 (1): 2237.

Thomas, R.Z. 2011. Tilling new soil: coverage of organic agriculture in farm journal, successful farming, and progressive farmer from 1985 to 2005. Ohio, USA: Ohio University.

Thomson, J., and L. Dininni. 2005. What the print media tell us about agricultural biotechnology: will we remember? choices: the magazine of food. Farm \& Resource Issues 20: 247.

Tilman, D., C. Balzer, J. Hill, and B.L. Befort. 2011. Global food demand and the sustainable intensification of agriculture. Proceedings of the National Academy of Sciences 108: 20260-20264.

Tourangeau, W. 2018. Power, discourse, and news media: examining Canada's GM alfalfa protests. Geoforum 91: 117-126.

Townsend, T.J., S.J. Ramsden, and P. Wilson. 2016. How do we cultivate in England? Tillage practices in crop production systems. Soil Use and Management 32: 106-117.

Ulrich-Schad, J.D., S. Garciá De Jalón, N. Babin, A. Pape, and L.S. Prokopy. 2017. Measuring and understanding agricultural producers' adoption of nutrient best management practices. Journal of Soil and Water Conservation 72: 506-518.

Walter, G. 1995. A “curious blend": the successful farmer in American farm magazines, 1984-1991. Agriculture and Human Values 12: $55-68$.

Walter, G. 1996. The ideology of success in major American farm magazines, 1934-1991. Journalism and Mass Communication Quaterly 73: 594-608.

Wanta, W., G. Golan, and C. Lee. 2004. Agenda setting and international news: media influence on public perceptions of foreign nations. Journalism and Mass Communication Quarterly 8: 364-377.

Zahry, N.R., and J.C. Besley. 2019. Genetic engineering, genetic modification, or agricultural biotechnology: does the term matter? Journal of Risk Research 22: 16-31.

Zaryan, S. 2017. Truth and trust: how audiences are making sense of fake news. Lund, Sweden: Lund University.

Publisher's Note Springer Nature remains neutral with regard to jurisdictional claims in published maps and institutional affiliations. 
Niki Rust, PhD, is the Tees-Swale: naturally connected Programme Manager. She is also the Founding Director of Be in the Change, a global non-profit www.beinthechange.club

Rebecca Jarvis, PhD, is a Postdoctoral Research Fellow at Auckland University of Technology and an Honorary Research Fellow at the Sydney Institute of Marine Science
Mark Reed, PhD, is a Professor based at the Thriving Natural Capital Challenge Centre, Department of Rural Economies, Environment \& Society, Scotland's Rural College (SRUC).

Julia Cooper, PhD, is based at the Institute for Agri-Food Innovation at Newcastle University, where she is a Senior Lecturer in Soil Science. 